\title{
The influence of the Surgical Operating Microscope in locating the mesiolingual canal orifice: a laboratory analysis
}

\section{Influência do Microscópio Cirúrgico na localização do canal mesiopalatino: uma análise laboratorial}

\author{
Tauby Coutinho Filho* \\ Renata Sá La Cerda** \\ Eduardo Diogo Gurgel Filho*** \\ Gustavo André de Deus**** \\ Karen Machado Magalhães**
}

\begin{abstract}
The aim of this study was to evaluate the influence of using the surgical operating microscope (SOM) for detection of the mesiolingual (ML) canal orifice in extracted first maxillary permanent molars. One hundred and eight human first maxillary permanent molars were randomly selected and mounted onto a dental chair mannequin. Conventional access cavity was prepared and an attempt was made to locate the mesiolingual canal orifice using only a sharp explorer, a mirror and a \#10 K-file. A mesiolingual canal orifice was either located or not located. If not located, the teeth were then evaluated by using a surgical operating microscope (SOM). The mesiobuccal roots of all teeth where the ML canal orifice had not been located were sectioned in an axial plane and the sections were explored with an adjunctive use of the SOM at a $25 \mathrm{X}$ magnification. ML canal orifices were detected in 58 teeth using only a sharp explorer, a mirror and \#10 K-file. In the remaining 50 teeth, 37 ML canal orifices were located by using the SOM and $3 \mathrm{ML}$ canal orifices were located after root sectioning. In 10 teeth, the ML canal orifices were not found. The results of this study showed a high incidence of a ML canal in the mesiobuccal roots of the first maxillary molars $(90.7 \%)$ and demonstrated that the adjunctive use of the SOM increased the ability of the dental clinician to locate the ML canal orifice.
\end{abstract}

DESCRIPTORS: Incidence; Dental pulp cavity; Microscopy.

RESUMO: O objetivo deste estudo foi avaliar a influência do uso do microscópio cirúrgico na localização do canal mesiopalatino (MP) em primeiros molares superiores humanos permanentes extraídos. Cento e oito primeiros molares superiores permanentes foram selecionados aleatoriamente e montados em um manequim dental. Uma cavidade de acesso convencional foi realizada e uma tentativa de se localizar o canal mesiopalatino foi feita, utilizando-se somente uma sonda exploradora afiada, um odontoscópio e uma lima tipo K tamanho 10. Quando não localizado o referido canal, os dentes foram então avaliados com auxilio de um microscópio cirúrgico (MC). As raízes mésio-vestibulares de todos os dentes nos quais o canal MP não foi localizado foram então seccionadas transversalmente e exploradas com auxilio do MC, com um aumento de $25 \mathrm{X}$. Os canais MP foram detectados em 58 dentes em que se usaram somente uma sonda exploradora afiada, um odontoscópio e uma lima tipo K tamanho 10. Nos 50 dentes restantes, 37 canais MP foram localizados com o auxílio do MC e 3 canais MP foram localizados após a secção das raízes. Em 10 dentes os canais MP não foram localizados. Os resultados deste estudo mostraram uma alta incidência do canal MP na raiz mésio-vestibular do primeiro molar superior permanente $(90.7 \%)$ e demonstraram que o uso adjunto do MC aumentou a capacidade do operador em localizar o canal MP.

DESCRITORES: Incidência; Cavidade da polpa dentária; Microscopia.

\section{INTRODUCTION}

The goals of successful endodontics are the total obliteration of the canal space and the perfect sealing of the apical foramen with an inert filling material. For this, the location and negotiation, with subsequent cleaning and shaping, of the root canal system are necessary. Pécora et al. ${ }^{11}$ (1992) affirms that one of the main reasons for the failure of root canal therapy is the lack of sufficient knowledge concerning the anatomy of teeth, both internal and external. The first maxil-

\footnotetext{
* PhD, Department of Endodontics; **Specialists in Endodontics; *** MSc, Department of Endodontics - Rio de Janeiro State University.

*** PhD, Department of Endodontics, University of Fortaleza.
} 
Coutinho Filho T, Cerda RSL, Gurgel Filho ED, Deus GA, Magalhães KM. The influence of the Surgical Operating Microscope in locating the mesiolingual canal orifice: a laboratory analysis. Braz Oral Res 2006;20(1):59-63.

lary molar is the most bulky teeth in the mouth, and has many anatomical variations. Usually both the distobuccal root and the palatal root present only one canal. The mesiobuccal root presents more anatomical variations, such as the number and disposition of the canals. Bjorndal, Skidmore ${ }^{2}$ (1983) affirmed that the difficulty in locating the mesiolingual canal (ML) during the first maxillary permanent molar endodontic treatment may have implications for the long-term prognosis.

Clinically, the presence or absence of the mesiolingual canal is limited by the conditions in which locating of the orifice is carried out. The ability to locate the mesiolingual canal depends on the skill of the operator, the complexity of the anatomy and the use of high power illumination and magnification techniques, such as that performed with the surgical operating microscope. A literature review has demonstrated wide variation in the prevalence of the ML canal mostly in in vitro researches. Hess ${ }^{6}$ (1925), in a classical study, reported finding 4 canals in $54 \%$ of first maxillary molars. Weine et al. ${ }^{16}(1969)$ evaluated first maxillary molars and located 4 canals in $62 \%$ of the teeth. Pineda, Kuttler ${ }^{12}$ (1972) evaluated the number of canals in first and second molars and found 4 canals in $51.5 \%$ of the teeth. Fogel et al. ${ }^{4}$ (1994) evaluated the use of $2.5 \mathrm{X}$ magnification telescopes with fiberoptic headlamps for locating the mesiolingual canals in first maxillary molars in vivo. They found that $71.2 \%$ of the mesiobuccal roots had two canals. Stropko ${ }^{15}$ (1999) found $73 \%$ to $93 \%$ of mesiolingual canals in a recent clinical study. Baldassari-Cruz et al. ${ }^{1}$ (2002) evaluated the influence of the dental operating microscope in locating the mesiolingual orifice. This study demonstrated that the adjunctive use of the dental operating microscope increased the ability of the clinician to locate a mesiolingual canal.

The purpose of this study was to evaluate whether the adjunctive use of the surgical operating microscope would increase detection of the mesiolingual canal orifice in the mesiobuccal root of first maxillary permanent molars.

\section{MATERIALS \& METHODS}

For this study, 108 human first maxillary left and right molars were selected randomly from the tooth bank of the Department of Endodontics, Rio de Janeiro State University.

The teeth were stored in 10\% neutral formalin. The sex and race of the patients from whom these teeth were obtained were unknown. The teeth were mounted onto a dental chair mannequin (Columbia Dentoform, Long Island, NY, USA). No isolation of the teeth by rubber dam was done. Without using magnification or headlamps, a conventional access cavity was prepared using a \#6 high-speed handpiece spherical bur (Dentsply-Maillefer, Ballaigues, Switzerland), a sharp endodontic explorer, a mirror, a \#10 K-file (Dentsply-Maillefer, Ballaigues, Switzerland) and water irrigation. After locating the mesiobuccal, distobuccal and palatal canals, an attempt was made to locate the mesiolingual canal orifice using only a sharp explorer, a mirror and a \#10 K-file. If the mesiolingual canal orifice was not located, a \#7001 low-speed hand-piece bur (Dentsply-Maillefer, Ballaigues, Switzerland) was used 2 or $3 \mathrm{~mm}$ into the orifice of the mesiobuccal canal where a trench was prepared in a lingual and slightly mesial direction through the mesial dentinal shelf ${ }^{1}$. The root was again explored by using only a sharp endodontic explorer, a mirror and a \#10 K-file in an attempt to locate a mesiolingual canal orifice.

A mesiolingual canal orifice was either located or not located. If not located the teeth were then evaluated by using a surgical operating microscope (Dental F. Vasconcelos, M900 -25 X, São Paulo, Brazil) at a magnification of $25 \mathrm{X}$. Again, an ML canal orifice was either located or not located. The mesiobuccal roots of all teeth where the ML canal orifice was not located were sectioned in an axial plane $6 \mathrm{~mm}$ below the cemento-enamel junction. The sections were explored using a sharp endodontic explorer, a mirror and a \#10 K-file (Figure $1 \mathrm{~F}$ ) with the adjunctive use of the surgical operating microscope at a magnification of $25 \mathrm{X}$ to determine the actual presence or absence of the orifice of the ML canal. In this methodology, each tooth served as its own control.

\section{RESULTS}

In the first phase of this methodology, with the use of only a sharp endodontic explorer, a mirror and a \#10 K-file (unaided vision), a total of $58 \mathrm{ML}$ canal orifices were detected out of 108 teeth $(53.7 \%)$. The 50 teeth where the ML canal orifices could not be located with unaided vision were submitted to evaluation under a surgical operating microscope (SOM). After this evaluation, a total of $37 \mathrm{ML}$ canal orifices were located (74\%). Thus, $37 \mathrm{ML}$ canal orifices could only be located with the use of the SOM. In the lab, after sectioning, 3 additional ML canal orifices were located in 
Coutinho Filho T, Cerda RSL, Gurgel Filho ED, Deus GA, Magalhães KM. The influence of the Surgical Operating Microscope in locating the mesiolingual canal orifice: a laboratory analysis. Braz Oral Res 2006;20(1):59-63.

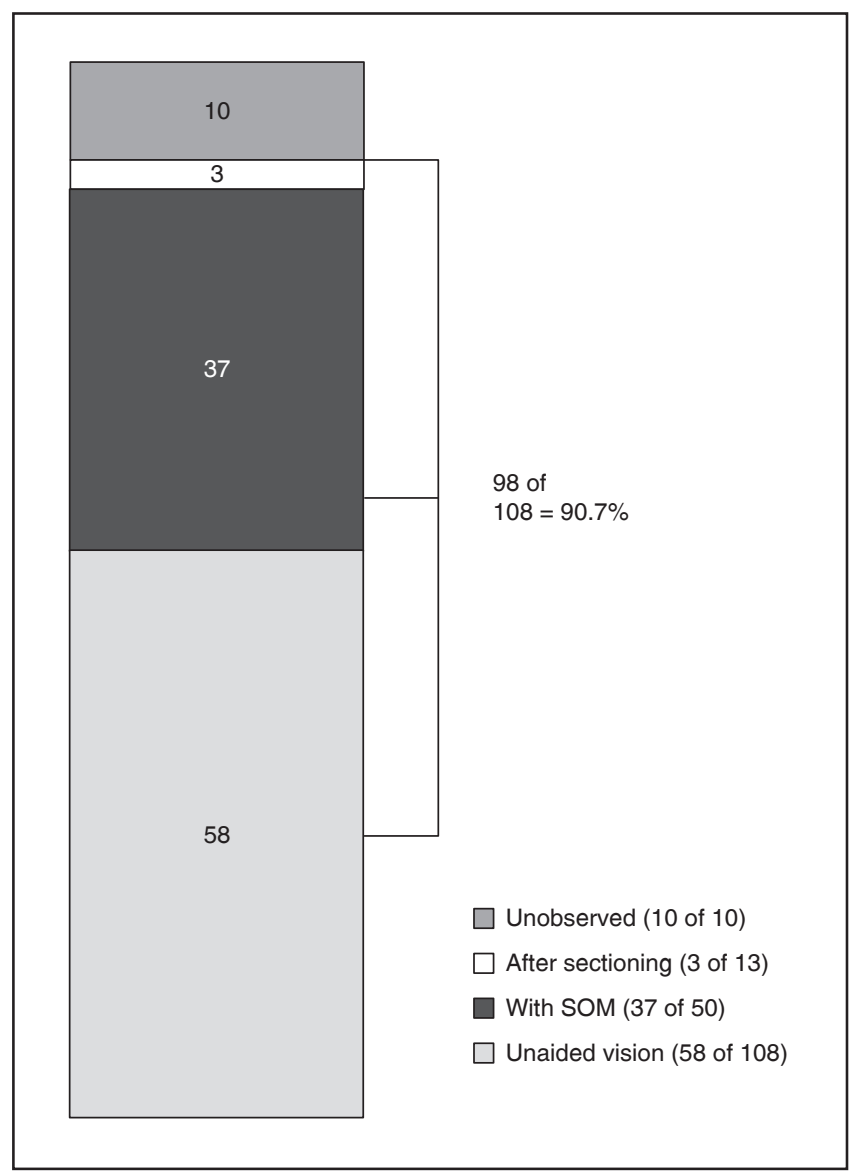

GRAPH 1 - Percentages of mesiolingual canals located with unaided vision (sharp explorer, mirror and a \#10 K-file), with the SOM (surgical operating microscope) and after sectioning.

the remaining 13 teeth $(23 \%)$. These 3 canals were located neither with the traditional methods nor with the SOM evaluation. A total of $98 \mathrm{ML}$ canal orifices were identified out of 108 experimental teeth (90.7\%). (Graph 1).

Figure $1 \mathrm{~A}$ shows one of the first maxillary molars used in this experiment and the presence of 4 distinct foramina (Figure 1B). Figure $1 \mathrm{C}$ shows an example of the difficulty in locating the ML canal orifice in the first maxillary molar, and Figure 1D summarizes the results of this work.

\section{DISCUSSION}

Successful endodontic treatment demands an adequate cleaning, shaping and filling of the root canal system. For this, the endodontist must have comprehensive knowledge about root canal morphology. Many types of root curvatures and other anatomical variations may be present in teeth subjected to endodontic treatment. If a root canal system is not located, this may reduce the chance of treatment success. In that perspective, the incidence of the ML canal in the mesiobuccal root of the first maxillary molar is always a matter of interest to the endodontic community. Baldassari-Cruz et al. ${ }^{1}$ (2002) related that the ML canal in mesiobuccal roots of maxillary first molars can be extremely difficult to locate clinically.

There is a significant difference in the incidence of the ML canal of the mesiobuccal root of first maxillary molar when evaluated in vitro and in vivo. Seidberg et al. ${ }^{14}$ (1973) reported a clinical incidence of $35 \%$, varying to $69 \%$ in vitro. Pomeranz, Fishelberg ${ }^{13}$ (1974) related findings closer to those of Seidberg et al. ${ }^{14}$ (1973), an incidence of approximately $69 \%$ of the ML canal in the mesiobuccal roots of first maxillary molars in vitro, and only $31 \%$ after in vivo evaluation. Hartwell, Bellizzi ${ }^{5}$ (1982) observed a divergence between the clinical incidence of the ML canal in first maxillary molars and the in vitro incidence. These findings show that locating of the mesiolingual canal is a difficult step in the first maxillary molar root canal treatment. Kulild, Peters ${ }^{7}$ (1990) found the incidence of a second canal in the mesiobuccal roots of the first and second maxillary molars to be approximately $95 \%$. The attention required for locating the ML canal is greater in young patients between 20 and 40 years of age, in accordance with Pineda, Kuttler ${ }^{12}$ (1972) and Neaverth et al. ${ }^{8}$ (1987).

The results of the present study demonstrate that $53.7 \%$ of the ML canal orifices were detected by using a sharp endodontic explorer, a mirror and a \#10 K-file. With the adjunctive use of the SOM, the incidence increased from $53.7 \%$ to $87.96 \%$. This result showed the efficacy of this clinical procedure. Carr $^{3}$ (1992) affirms that the operating microscope has greatly improved the ability of the endodontist to visualize and treat periapical pathology in endodontic surgery. It has also enhanced the practice of nonsurgical endodontics. The higher magnification and illumination can be useful for access cavity preparation, instrumentation and obturation. It can improve the clinician's view of the complexity of the root canal anatomy and aid in the location of additional canals, fins or ribbons. Thus, the use of the SOM to detect the ML canal orifice of first and second maxillary molars may enhance the success of endodontic procedures.

In a recent study, Baldassari-Cruz et al. ${ }^{1}$ (2002), using a very similar methodology to that of this study, observed a prevalence of $90 \%$. However, 
Coutinho Filho T, Cerda RSL, Gurgel Filho ED, Deus GA, Magalhães KM. The influence of the Surgical Operating Microscope in locating the mesiolingual canal orifice: a laboratory analysis. Braz Oral Res 2006;20(1):59-63.
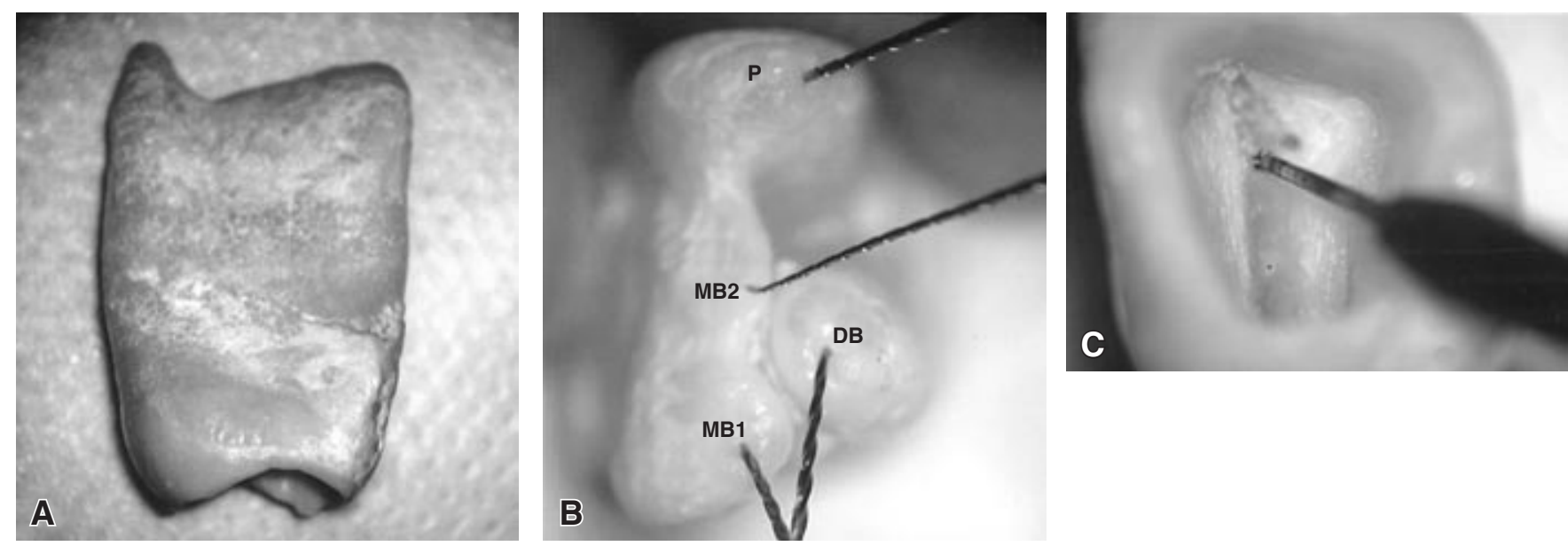

FIGURE 1A THROUGH C - One of the first maxillary molars used in this experiment (A). By inspecting the roots foramina, we can see the presence of four canals (B). Surgical microscope with the aid of a long neck bur to find the ML canal, after the unaided vision technique had been used and failed (C).
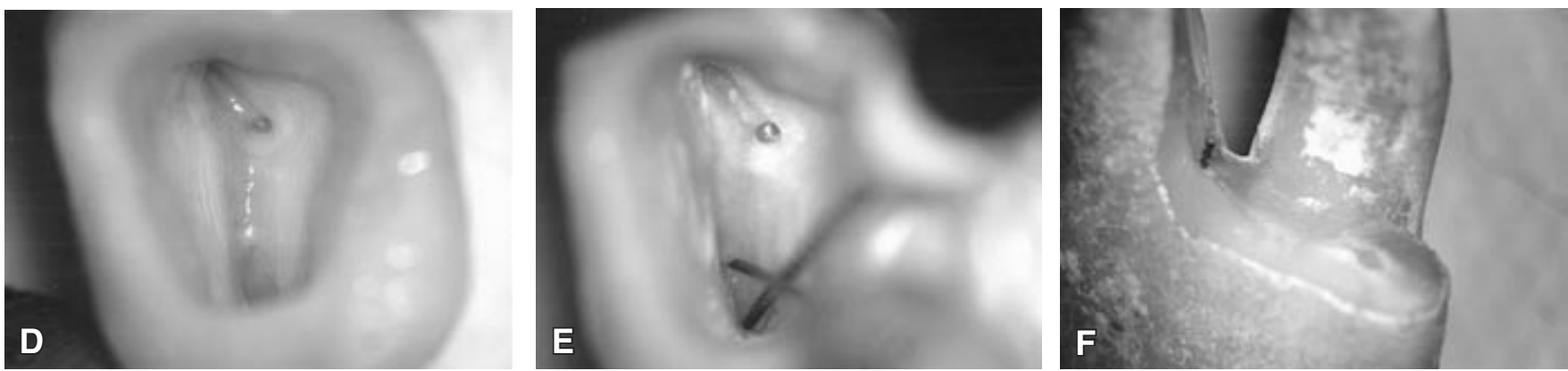

FIGURE 1D THROUGH F - Aspect of the final access cavity (D). Locating of a fourth canal in an unusual anatomical area, next to the palatal canal $(\mathbf{E})$. Sectioned root showing the mesiobuccal and the mesiolingual canals, which are distinct canals (F).

another group of studies demonstrated a reduced incidence of the ML canal, around 50\%5,6,9,10,16. We believe that these different values can be accounted for by the different methodology adopted by those researches, especially regarding the difficulty in obtaining appropriate standardization of the variables of anatomical researches.

Conservative or small access cavity preparations are not recommended because some missed canals can lead to root canal therapy failure. Weller, Hartwell ${ }^{17}$ (1989) have stated that there is an increased probability of finding the mesiolingual canal if the initial access is changed from a classical triangular shape to a more rhomboidal shape. Modification of the access cavity (to a rhomboidal shape) to include a trench preparation from the mesiobuccal canal to a mesiopalatal direction, where the ML canal orifice may be typically found, increases the frequency of ML canal orifice detection. Once a rhomboidal access shape has been established and all major canals have been located, a careful examination of the pulpal floor should be conducted. Baldassari-Cruz et al. ${ }^{1}$ (2002) related that different access cavity shapes increase the frequency of locating the ML canal in the mesiobuccal root of the first maxillary molar (Figure 1E). The surgical operating microscope is very useful in performing this task. Combined with the knowledge about root canal system morphology and accessibility, enhanced vision to the area allows the operator to achieve maximum results. This is confirmed by the high prevalence of the ML canal orifice found in this study.

The negotiation as well as the cleaning and shaping of the ML in the mesiobuccal roots of first maxillary permanent molars was not part of this study. We believe that a great number of these canals are impossible to be treated by methods used in endodontics nowadays. This represents an interesting theme for future researches. 
Coutinho Filho T, Cerda RSL, Gurgel Filho ED, Deus GA, Magalhães KM. The influence of the Surgical Operating Microscope in locating the mesiolingual canal orifice: a laboratory analysis. Braz Oral Res 2006;20(1):59-63.

\section{CONCLUSION}

Our study showed a high incidence of the ML canal in the mesiobuccal roots of first maxillary

\section{REFERENCES}

1. Baldassari-Cruz LA, Lilly JP, Rivera EM. The influence of dental operating microscope in locating the mesiolingual canal orifice. Oral Surg Oral Med Oral Pathol Oral Radiol Endod 2002;93(2):190-4.

2. Bjorndal AE, Skidmore AE. Anatomy and morphology of human teeth. Research summary pamphlet. Iowa City: University of Iowa Press; 1983.

3. Carr GB. Microscopes in endodontics. J Calif Dent Assoc 1992;20(11):55-61.

4. Fogel HM, Peikoff MD, Christie WH. Canal configuration in the mesiobuccal root of the maxillary first molar: a clinical study. J Endod 1994;20(3):135-7.

5. Hartwell G, Bellizzi R. Clinical investigation of in vivo endodontically treated mandibular and maxillary molars. J Endod 1982;8(12):555-7.

6 . Hess W. The anatomy of the root canals of the teeth of the Permanent dentition. New York: Williams Wood; 1925.

7. Kulild JC, Peters DD. Incidence and configuration of canal systems in the mesiobuccal root of maxillary first and second molars. J Endod 1990;16(7):311-7.

8. Neaverth EJ, Kotler LM, Katenbach RF. Clinical investigation (in vivo) of endodontically treated maxillary first molars. J Endod 1987;13(10):506-12.

9. Nosonowitz DM, Brenner MR. The major canals of the mesiobuccal root of the maxillary first and second molars. $\mathrm{N}$ Y J Dent 1973;43(1):12-5. molars (92\%) and demonstrated that the adjunctive use of the SOM increases the ability to detect an ML canal orifice.

10. Okumura T. Anatomy of the root canals. J Am Dent Assoc 1927;14(4):632-6.

11. Pécora JD, Woelfel JB, Sousa Neto MD, Issa EP. Morphologic study of the maxillary molars. Part II: Internal Anatomy. Braz Dent J 1992;3(1):53-7.

12. Pineda F, Kuttler Y. Mesiodistal and buccolingual roentgenographic investigation of 7,275 root canals. Oral Surg Oral Med Oral Pathol 1972;33(1):101-10.

13. Pomeranz H, Fishelberg G. The secondary mesiobuccal canal of maxillary molars. J Am Dent Assoc 1974;88(1):119-24.

14. Seidberg BH, Altman M, Guttuso J, Suson M. Frequency of two mesiobuccal root canals in maxillary permanent first molars. J Am Dent Assoc 1973;87(4):852-6.

15. Stropko JJ. Canal morphology of maxillary molars: clinical observations of canal configurations. J Endod 1999;25(6):446-50.

16. Weine FS, Healey HJ, Gerstein H, Evanson L. Canal configuration in the mesiobuccal root of the maxillary first molar and its endodontic significance. Oral Surg Oral Med Oral Pathol 1969;28(3):419-25.

17. Weller RN, Hartwell GR. The impact of improved access and searching techniques on detection of the mesiolingual canal in maxillary molars. J Endod 1989;15(2):82-3.

Received for publication on Jul 05, 2005

Sent for alterations on Sep 23, 2005

Accepted for publication on Nov 29, 2005 